\title{
A cultura do Carthamus tinctorius L.: Principais usos e variabilidade genética
}

\author{
The culture of Carthamus tinctorius L.: Main uses and genetic variability \\ El cultivo de Carthamus tinctorius L.: Principales usos y variabilidad genética
}

Recebido: 04/02/2021 | Revisado: 06/02/2021 | Aceito: 06/02/2021 | Publicado: 09/02/2021

\author{
Altacis Junior de Oliveira \\ ORCID: https://orcid.org/0000-0002-6787-7160 \\ Universidade do Estado de Mato Grosso, Brasil \\ E-mail: altacismarquesfig@hotmail.com
}

\begin{abstract}
Resumo
O Carthamus tinctorius L. é uma das espécies mais antigas do mundo, é uma oleaginosa pertencente à família Asteraceae, cuja matéria-prima é destinada para diversos fins. A cultura tem atraído a atenção de pesquisadores e indústrias por possuir alta qualidade e quantidade de óleo, neste contexto o que torna importante a realização de estudos, principalmente no melhoramento genético, que auxilia na seleção de genótipos superiores. Diante disso, o presente trabalho objetivou-se desenvolver uma revisão de literatura sobre a cultura do cártamo, mostrando algumas informações sobre seu cultivo, principais usos e sobre a variabilidade genética da mesma. Através do estudo feito em artigos científicos, livros e periódicos pode-se familiarizar os leitores sobre a cultura do cártamo, pois ainda no Brasil é pouco estudada e informações principalmente sobre seu cultivo e produção ainda são escassas, mas alguns trabalhos apresentados mostra o potencial que o Brasil tem para o cultivo do cártamo, sendo necessários estudos de melhoramento genético para extrair o máximo potencial da espécie.
\end{abstract}

Palavras-chave: Cártamo; SSR; Melhoramento Genético.

\begin{abstract}
The Carthamus tinctorius L. is one of the oldest species in the world, it is an oleaginous belonging to the Asteraceae family, whose raw material is destined for several purposes. The culture has attracted the attention of researchers and industries for having high quality and quantity of oil, in this context which makes it important to conduct studies, especially in genetic improvement, which helps in the selection of superior genotypes. Therefore, the present work aimed to develop a literature review on safflower culture, showing some information on its cultivation, main uses and genetic variability. Through the study done in scientific articles, books and journals it is possible to familiarize the readers about safflower culture, because still in Brazil it is little studied and information mainly about its cultivation and production are still scarce, but some presented works show the potential that Brazil has for safflower cultivation, being necessary genetic improvement studies to extract the maximum potential of the species. Incluir o resumo em inglês.
\end{abstract}

Keywords: Safflower; SSR; Genetic Improvement.

\begin{abstract}
Resumen
Carthamus tinctorius L. es una de las especies más antiguas del mundo, es una oleaginosa perteneciente a la familia de las Asteraceae, cuya materia prima se destina a diversos fines. La cultura ha atraído la atención de investigadores e industrias por tener alta calidad y cantidad de aceite, en este contexto lo que hace importante la realización de estudios, principalmente en el mejoramiento genético, que ayuda en la selección de genotipos superiores. Por ello, el presente trabajo tuvo como objetivo desarrollar una revisión bibliográfica sobre el cultivo del cártamo, mostrando algunas informaciones sobre su cultivo, principales usos y variabilidad genética. A través del estudio realizado en artículos científicos, libros y revistas, el lector puede familiarizarse con el cultivo del cártamo, ya que aún es poco estudiado en Brasil y la información sobre su cultivo y producción es todavía escasa, pero algunos estudios presentados muestran el potencial que tiene Brasil para el cultivo del cártamo, siendo necesarios estudios de mejoramiento genético para extraer el máximo potencial de la especie.Incluir o resumo em espanhol.
\end{abstract}

Palabras clave: Cártamo; SSR; Mejora genética.

\section{Introdução}

A cultura do cártamo (Carthamus tinctorius L.) é uma das mais antigas do mundo, com relatos de seu cultivo e utilização a mais de 4.000 anos (Moura et al., 2015). É considerada uma oleaginosa pertencente à família Asteraceae, cuja matéria-prima é destinada para produção de óleo na alimentação humana e na indústria para diversos fins (Queiroga et al., 
2020), bem como na produção de lubrificantes, biocombustíveis, sabões e vernizes, óleo de cozinha e ração para animais (Golkar 2014, Kumar et al., 2016).

A cultura do cártamo ocupa a oitava posição entre as espécies produtoras de óleo, destacando-se como uma das mais importantes oleaginosas do mundo (Sharifi et al., 2017). Seu cultivo é feito em mais de 60 países, e a produção mundial no ano de 2017 foi em torno de 734 mil toneladas, em uma área cultivada de aproximadamente de 725 mil hectares,. Destacar os três primeiros países mais produtores. Dentre eles, Cazaquistão contribuiu com 35 \% da área plantada (FAO, 2019).

No Brasil a cultura tem atraído a atenção de pesquisadores e indústrias por se tratar de uma oleaginosa com características especiais (citar as características especiais), as quais estão relacionadas, a quantidade e qualidade do seu óleo (Silveira et al., 2017; FAO, 2019). Além disso, estudos envolvendo a cultura ainda são escassos no país, principalmente do melhoramento genético, que podem ajudar na escolha e seleção de genótipos que melhor se desenvolveriam nas regiões produtoras (Singh \& Nimbkar, 2016).

Nesse contexto, a avaliação da variabilidade genética com o uso de marcadores é primordial para exploração dos recursos genéticos em programas de melhoramento de plantas (Saadaoui et al., 2017). A diversidade genética pode ser avaliada usando diferentes marcadores (bioquímicos, morfológicos e moleculares), sendo que a variação genética no nível do DNA constitui uma excelente ferramenta para a obtenção de informações contidas no genoma de um indivíduo (Vieira et al., 2008; Bahmankar et al. 2017).

Uma ferramenta muito utilizada para a análise de diversidade genética são os marcadores moleculares SSR (Simple Sequence Repeat) que são capazes de identificar genótipos com características desejáveis para o desenvolvimento de novas cultivares (Kiran et al., 2017). Atualmente, os marcadores moleculares SSR têm sido utilizado para estudos genéticos em cártamo e na obtenção da estrutura genética (Golkar \& Mokhtari, 2018).

A presente revisão bibliográfica busca aprofundar o conhecimento sobre a utilização de técnicas moleculares para o melhoramento genético da cultura, pois auxiliam na identificação da variabilidade genética e estrutura populacional. Ambas as informações são de fundamental importância para o uso racional da diversidade genética das populações de cártamo.

Diante disso, o presente trabalho objetivou-se desenvolver uma revisão de literatura sobre a cultura do cártamo, mostrando algumas informações sobre seu cultivo, principais usos e sobre a variabilidade genética da mesma. Use o parágrafo como modelo (fonte: TNR 10 - justificado - espaço 1,5).

\section{Metodologia}

O estudo apresentado nesse trabalho foi por meio de pesquisa bibliográfica, abordando a cultura do Carthamus tinctorius L., principais usos do cártamo e variabilidade genética. Foram realizadas pesquisas em livros, artigos científicos e periódicos, buscando conhecer o tema e ampliando o grau de conhecimento.

\section{A Cultura do Carthamus tinctorius $\mathbf{L}$.}

O Carthamus tinctorius L. conhecido também como cártamo, açafrão e açafrão bastardo é considerado uma das culturas mais antigas do mundo, os relatos de seu cultivo e utilização datam a mais de 4.000 anos (Medeiros, 2011). Sua origem é Asiática e Africana com prováveis centros de distribuição na Índia, Afeganistão e Etiópia (Moura et al., 2015). Na antiguidade era utilizado como corante extraído das flores, muito usado em alimentos e tecidos, com evidências de cultivo datadas em 1.600 a.C. no Egito (Sehgal, 2011; Britannica Academic, 2019).

No século XX, a cultura foi introduzida nas Américas nos Estados Unidos, nos Estados do Arizona, Califórnia, Nebraska e Utah (Ashri et al.,1960, Dajue et al., 1996; Silva, 2013). Devido à adaptabilidade da cultura, no ano de 1958 o cártamo passou a ser cultivado na região noroeste do México (Coronado, 2010). No Brasil seu histórico de cultivo é recente, 
realizado apenas por Universidades e institutos de pesquisas, visando posicionar a semeadura do cártamo na segunda safra (Zoz, 2015).

O cártamo é uma oleaginosa pertencente à família Asteraceae, gênero Carthamus e espécie Carthamus tinctorius L., é a única do gênero que possui 24 cromossomos (Gerhardt, 2014). O porte é herbáceo, caule ereto e ramificado, com altura variando entre 0,4 e 2,0 m, com sistema radicular pivotante que pode atingir até 3,0 m de profundidade (Singh e Nimbkar, 2007; Neto, 2020).

Seu sistema radicular consegue se desenvolver bem, favorecendo a capacidade de absorção de água e nutrientes em maiores profundidades (Sajedi, 2012). Esse mecanismo proporciona a cultura uma característica importante, tornando esta uma alternativa para o cultivo em regiões sujeitas ao estresse hídrico (Kar et al., 2007), ou para ser inclusa como cultivo em período de segunda safra onde pode ocorrer veranicos.

As ramificações do caule podem ser classificadas como primárias, secundárias e terciárias, nas quais surge uma inflorescência chamada de capítulo (Britannica Academic, 2019). O capítulo é composto de 20 a 250 flores, denominada de floretes que se encontram envolvidas por diversas brácteas sobrepostas (Silva, 2013). Cada flor possui um conjunto de pétalas que circunda o gineceu e androceu (Singh e Nimbkar, 2006).

Sua reprodução ocorre predominantemente pela autofecundação, com uma taxa superior a $90 \%$, mas, no seu germoplasma podem ser encontrados genótipos com uma taxa de cruzamento em torno de 50\%. O inseto que mais tem importância nesse cruzamento é a abelha, pois o vento tem pouca influência no transporte do pólen. Embora a cultura apresente uma taxa considerável de cruzamentos, os métodos de melhoramento empregados são aqueles comumente destinados para espécies autógamas (Dajue et al., 1996).

A semente do cártamo é eurispérmica, pois apresenta formato irregular com ápice achatado e base arredondada, possui coloração branca amarelada quando seca e acinzentada quando hidratada (Mündel et al., 2004; Abud et. al., 2010). Os genótipos comerciais de cártamo são classificados em dois grupos conforme os seus teores e a composição do óleo presente nas sementes. O primeiro grupo chamado de oleico é definido por apresentar de 70 a 75\% de ácidos graxos na sua constituição, e o segundo grupo denominado de linoleico apresentando na sua constituição acima de 70\% de ácido linoleico (Gracia et al., 2010).

O ciclo varia em torno de 110 a 150 dias, que pode antecipar ou prolongar seu ciclo, dependendo do genótipo e das condições ambientais (Flemmer et al., 2015). Após a semeadura, a germinação ocorre entre 3 a 8 dias, onde se inicia o estádio de roseta, que é caracterizado pelo crescimento lento da planta, onde diversas folhas são produzidas ao nível do solo. O material genético e as condições climáticas podem influenciar na duração desta fase, mas geralmente dura em torno de três a seis semanas. Essa é a etapa mais crítica do desenvolvimento da cultura, pois apresenta um crescimento lento, que torna bastante sensível à competição por água, luz e nutrientes com as plantas invasoras (Emongor, 2010).

A fase de desenvolvimento vegetativo ocorre de 42 a 48 dias após a emergência (DAE), obtendo a elongação do caule e as ramificações. O florescimento inicia entre 60 e 100 DAE. Esta fase é de extrema importância para a cultura, pois é quando os componentes de produção são determinados. O estádio de maturidade fisiológica está compreendido entre 102 a 148 DAE, onde ocorre a translocação de fotoassimilados do caule e folhas (fonte) para os grãos (dreno) (Montoya, 2010). Já o ponto ideal para colheita se dá entre 117 a 169 DAE, época caracterizada com as plantas completamente senescidas com coloração marrom das folhas e capítulos e as sementes apresentando umidade em torno de 10\% (Emongor, 2010; Guidorizzi, 2016).

O cártamo possui elevada capacidade de adaptação às mais diferentes condições edafoclimáticas, tem um bom desenvolvimento em altitudes situadas até 1000 metros acima do nível do mar. Tolera grandes amplitudes de temperatura que podem variar de 5 a $40{ }^{\circ} \mathrm{C}$ (Oelke et al., 1992), com uma temperatura ótima situada entre 20 e $35{ }^{\circ} \mathrm{C}$ (Coronado, 2010). Possui pouca ou nula resposta ao fotoperíodo e tem adaptação excelente em regiões com precipitações de 300 a 400 mm durante o seu 
ciclo de desenvolvimento. Apresenta tolerancia à seca, sendo que em condições de deficiência hídrica moderada pode apresentar ligeira redução da produtividade de grãos (Hussain et al., 2015). O cultivo ainda pode ser em diferentes tipos de solo, desde que sejam profundos e possuam boa drenagem (Bagheri e Sam-Dailiri, 2011).

Sabe-se, que nas regiões sudeste e centro-oeste do Brasil, as áreas agricultáveis predominam um longo período de estiagem, normalmente na segunda quinzena de abril até o final de setembro (Coronado, 2010; Shahrokhnia et al., 2016). Quando se colhe tardiamente a cultura primária ou de verão, ou seja, a partir do final de fevereiro, sendo muito arriscada a semeadura de espécies tradicionais. Tornando estas áreas alternativas para cultivar espécies como o cártamo, que é tolerante a deficiência hídrica, propiciando aos produtores opções interessantes de cultivo de entressafra (Guidorizzi, 2016; Paludo et al., 2018).

O cultivo do cártamo é feito em mais de 60 países, em 2017 a produção mundial foi em torno de 734 mil toneladas, em uma área cultivada de aproximadamente de 725 mil hectares. O país que possui maior área produtora da cultura é o Cazaquistão com aproximadamente 251 mil hectares, representando quase 35\% da área total colhida no mundo em 2017, com uma produção de aproximadamente 225 toneladas. Quando se fala em produtividade da cultura, a Turquia lidera seguida pelo México, China, Estados Unidos e Hungria, com uma produtividade média de aproximadamente 1.826,00, 1.565,00, 1.429,00, $1.408,00$ e 1.286,00 kg ha-1 respectivamente (FAO, 2019).

Segundo os dados da FAO (2019), o Brasil não aparece na lista como produtor de cártamo, pois ainda é pouco cultivado no país. Alguns trabalhos vêm sendo realizados, principalmente pela Universidade Estadual Paulista "Júlio de Mesquita Filho" em Botucatu-SP, demonstrando a aptidão para a produção do cártamo.

Silva (2013) avaliando acessos de cártamo obteve produtividade média de 1.057,00 kg ha-1. Zoz (2015) avaliando variedades comerciais americanas obteve produtividade de 516,00 kg ha-1 em condições de restrição hídrica extrema, passando por uma estiagem de 51 dias na fase reprodutiva da cultura. Guidorizzi (2016) trabalhando com manejo e adubação obteve produtividades de até $2.119,00 \mathrm{~kg}$ ha- 1 .

Diante dos trabalhos apresentados fica nítido o potencial que o Brasil tem para o cultivo do cártamo, sendo necessários estudos de melhoramento genético para extrair o máximo potencial da espécie.

\section{Principais Usos do Cártamo}

As sementes de cártamo apresentam teores de óleo que variam de 35\% até $45 \%$, sendo este óleo considerado de alta qualidade, pois pode ser usado tanto para o consumo humano quanto para o uso industrial. $\mathrm{O}$ mesmo possui elevados teores de ácido oleico e ácido linoleico (70 - 75\%) e a sua classificação dos cultivares é dada por grupos, conforme os teores de ácidos graxos, ou seja, existe o grupo de cártamo oleico e o grupo de cártamo linoleico (Handan et al., 2009).

Os principais derivados do cártamo destinados ao consumo humano são o óleo de cozinha e margarina, também é utilizado como suplemento nutricional, devido possuir presença majoritária dos ácidos oleicos (Ômega 9) e linoleicos (Ômega 6), que auxilia no controle do colesterol ruim, na queima de gorduras e tonificação dos músculos (Medeiros, 2011).

Algumas pesquisas relacionadas ao consumo do óleo de cártamo demostraram ser benéfico à saúde, entre os benefícios descritos na literatura destacam-se a prevenção e o tratamento de hiperlipidemia (com redução nas concentrações de triglicerídeos, colesterol total e Lipoproteína de Baixa Densidade - LDL); estimulação do sistema imunológico; redução das lesões ateroscleróticas, prevenindo doenças cardíacas e hipertensão. Ajuda o organismo a queimar a gordura acumulada, liberando também uma substância que ajuda a reduzir o apetite, enviando ao cérebro comandos de saciedade, além disso, o óleo de cártamo tem a capacidade de auxiliar na definição da musculatura (Florien, 2019).

Para as indústrias, o óleo de cártamo pode ser empregado na fabricação de vários produtos como: tintas, vernizes, esmaltes, sabões, biodiesel, entre outros. A torta constituída da moagem dos grãos, subproduto obtido pelas indústrias de 
óleo, serve como boa fonte proteica, possuindo mais ou menos $25 \%$ de proteína, além da produção de biomassa, conferindo a esta cultura uma característica de forrageira de boa qualidade para produção de silagem, propícia para alimentação de ruminantes (Ekin, 2005; Arantes, 2011; Augustinho, 2013). O cártamo serve ainda para outros fins, como na alimentação de pássaros, planta ornamental, fins medicinais atuando em diversas anomalias e na alimentação humana por meio de subprodutos oriundos das sementes (Danieli et al., 2011).

Esta cultura tem diferentes formas de utilização, como é o caso de alguns países da Europa que o utilizam como planta ornamental (Magalhães, 2017), em outros países é utilizada para rotação de cultura, para controlar plantas daninhas e interromper ciclos de doenças, proporcionando uma diversificação dos sistemas de cultivo (Omidi et al., 2012). No Brasil, a cultura ainda possui pouca expressão econômica, principalmente por existir pouco conhecimento de manejo, tornando-se indispensável a realização de mais pesquisas (Zoz, 2012; Silva, 2013; Gehard, 2014).

\section{Variabilidade Genética}

O estudo da variabilidade genética de uma espécie é de fundamental importância, pois ela é a base para a evolução das espécies aos variados tipos de hábitats e às alterações climáticas, além de ser a base para programas de melhoramento genético. A quantificação da variabilidade genética dentro de populações pode ser efetuada a partir de medidas de diversidade genética intrapopulacional, que poderão ser estimadas a partir de dados de marcadores moleculares (Cavers et al., 2005; Saadaoui et al., 2017).

Os marcadores moleculares são quaisquer fenótipos moleculares provenientes de quaisquer segmentos expressos ou não de DNA que vem de herança genética e se prestam à diferenciação de um ou mais indivíduos (Ferreira e Grattapaglia, 1998; Milach, 1998). Esses marcadores moleculares podem ser obtidos por meio de diferentes técnicas, em que cada técnica utiliza uma estratégia particular para detectar o polimorfismo, nos quais, a diferença entre si é dada por características como a abundância no genoma, níveis de polimorfismo detectados, especificidade de locus, reprodutibilidade, requerimentos técnicos e custo (Mondini et al., 2009).

Conforme a metodologia utilizada para identificar os marcadores moleculares, pode-se classificá-los em dois grupos: o primeiro, os marcadores são obtidos por hibridização e o segundo, os marcadores são obtidos por amplificação do DNA. Entre os identificados por hibridização estão os marcadores RFLP (Restriction Fragment Length Polymorphism) e os marcadores minissatélites. Já para os marcadores por amplificação estão o RAPD (Random Amplified Polymorphic DNA), SCAR (Sequence Characterized Amplified Regions), STS (Sequence Tagged Sites), AFLP (Amplified Fragment Length Polymorphism) e SSR ou microssatélites (Simple Sequence Repeats) (Chies et al., 2014).

O aperfeiçoamento das técnicas utilizando marcadores por amplificação é fundamentada pela amplificação dos fragmentos de DNA, com isso, grandes avanços veem sendo alcançados na área dos marcadores de DNA, como é o caso dos marcadores de microssatélites (Padilha et al., 2003; Miah et al., 2013). Os marcadores de microssatélites são curtas regiões do DNA com não mais do que seis nucleotídeos de comprimento, repetidas em tandem ao longo do genoma (Litt e Luty, 1989; Ferreira e Gratapaglia, 1998). Por meio da reação de polimerase em cadeia (PCR) essas regiões são amplificadas, utilizando primers específicos (de 20 a 30 bases), complementares a sequências únicas que flanqueiam o microssatélite, assim, cada segmento amplificado de tamanho diferente representa um alelo diferente do mesmo loco (Ferreira e Gratapaglia, 1998).

As principais vantagens dos marcadores de microssatélites é de serem codominantes, bastante informativos, exigir pequena quantidade de DNA, ser de fácil utilização e reprodutibilidade, baixo custo, grande poder de resolução, e finalmente por constituírem uma das classes mais polimórficas de marcadores moleculares disponíveis hoje, diante disso, estão substituindo rapidamente outros marcadores em diversos tipos de estudos genéticos (Caixeta et al., 2006). 
Alguns estudos mostram a utilidade de marcadores SSR na cultura do cártamo, Chapman et al. (2009) avaliando o desenvolvimento, polimorfismo e utilidade cruzada de táxons em 27 genótipos de cártamo por meio de 104 marcadores SSR, observaram que os marcadores representaram um recurso valioso para a análise genética de cártamo e espécies relacionadas, e teve potencial de facilitar análises comparativas baseadas em mapas em uma ampla gama de táxons dentro das Asteraceae.

Derakhshan et al. (2014) avaliando a diversidade genética e as relações de 42 genótipos de cártamo em seis espécies, incluindo Carthamus tinctorius, Carthamus palaestinus, Carthamus oxyacanthus, Carthamus lanatus, Carthamus dentatus e Carthamus boissieri, utilizando 33 marcadores SSR, concluíram que os marcadores revelaram efetivamente as relações genéticas e a diversidade das espécies de Carthamus.

Kiran et al. (2017) observando características agronômicas, diversidade genética e estrutura populacional em 148 genótipos de cártamo oriundos de 15 países a partir da genotipagem de 44 loci SSR, detectaram, alta variação fenotípica, sugerindo que o subconjunto central pode ser explorado para o mapeamento da associação dos componentes de produção de sementes de cártamo.

Já Mokhtari et al. (2018) avaliando relações genéticas entre 105 genótipos de cártamo de diferentes áreas geográficas, por meio de 32 loci SSR, verificaram que os cromossomos domesticados e genótipos selvagens foram agrupados em dois grandes grupos, indicando esses marcadores como ferramenta apropriada para analisar a diversidade genética e mapeamento do genoma.

\section{Conclusão}

Através do estudo feito em artigos científicos, livros e periódicos pode-se familiarizar os leitores sobre a cultura do cártamo, pois ainda no Brasil é pouco estudado e informações principalmente sobre seu cultivo e produção ainda são escassas, mas alguns trabalhos apresentados mostra o potencial que o Brasil tem para o cultivo do cártamo, sendo necessários estudos de melhoramento genético para extrair o máximo potencial da espécie.

Novas pesquisas podem ser realizadas utilizando mais meios que geram informações, proporcionando um maior detalhamento sobre a cultura do Cártamo.

\section{Referências}

Abud, H. F., Gonçalves, N. R., Reis, R. D. G. E., Gallão, M. I., \& Innecco, R. (2010). Morfologia de sementes e plântulas de cártamo. Revista Ciência Agronômica, 41(2), 259-265.

Ambreen, H., Kumar, S., Variath, M. T., Joshi, G., Bali, S., Agarwal, M., \& Goel, S. (2015). Development of genomic microsatellite markers in Carthamus tinctorius L. (safflower) using next generation sequencing and assessment of their cross-species transferability and utility for diversity analysis. PLoS One, 10(8), e0135443.

Arantes, A. M. (2011). Cártamo (Carthamus tinctorium L.) produção de biomassa, grãos, óleo e avaliação nutritiva da silagem. Alcides Meneghelli Arantes. Dissertação. Nova Odessa-SP.

Ashri, A., \& Knowles, P. F. (1960). Cytogenetics of Safflower (Carthamus L.) Species and Their Hybrids 1. Agronomy Journal, $52(1), 11-17$.

Augustinho, E. T. (2013). Silagem e torta de cártamo na alimentação de ovinos como alternativa à silagem de milho e farelo de soja. Erika Turim Augustinho. Dissertação. Nova Odessa-SP.

Bagheri, H., \& Sam-Daliri, M. (2011). Effect of water stress on agronomic traits of spring safflower cultivars (Carthamus tinctorius L.). Australian Journal of Basic and Applied Sciences, 5(12), 2621-2624.

Bahmankar, M., Nabati, D. A., \& Dehdari, M. (2017). Genetic relationships among Iranian and exotic safflower using microsatellite markers. Journal of Crop Science and Biotechnology, 20(3), 159-165.

Barati, M., \& Arzani, A. (2012). Genetic diversity revealed by EST-SSR markers in cultivated and wild safflower. Biochemical Systematics and Ecology, 44, $117-123$.

Britannica, A. (2019). Safflower recuperado de: https://academicebbritannica.ez87.periodicos.capes.gov.br/levels /collegiate /article/s afflower/64715.

Caixeta, Oliveira, Brito, Sakauama. (2006). Tipos de marcadores moleculares. Viçosa: UFV. 
Cavers, S., Degen, B., Caron, H., Lemes, M. R., Margis, R., Salgueiro, F., \& Lowe, A. J. (2005). Optimal sampling strategy for estimation of spatial genetic structure in tree populations. Heredity, 95(4), 281-289.

Chapman, M. A., Hvala, J., Strever, J., Matvienko, M., Kozik, A., Michelmore, R. W., \& Burke, J. M. (2009). Development, poly morphism, and cross-taxon utility of EST-SSR markers from safflower (Carthamus tinctorius L.). Theoretical and Applied Genetics, 120(1), 85-91.

Coronado, L. M. (2010). El cultivo del cártamo (Carthamus tinctorius L.) en México.

de Souza Chies, T. T., Burchardt, P., Alves, E. M. S., Essi, L., \& dos Santos, E. K. (2014). O estudo da biodiversidade e evolução vegetal através de marcadores de DNA e citogenética: exemplos em Iridaceae e Poaceae. Ciência e Natura, 36, 279-293.

Dajue, L., \& Mündel, HH (1996). Cártamo, Carthamus tinctorius L (Vol. 7). Bioversity International.

Damodaram, T., \& Hegde, D. M. (2002). Oilseeds situation: a statistical compendium. Directorate of Oilseeds Research.

Danieli, P. P., Primi, R., Ronchi, B., Ruggeri, R., Rossini, F., Del Puglia, S., \& Cereti, C. F. (2011). The potential role of spineless safflower (Carthamus tinctorius L. var. inermis) as fodder crop in central Italy. Italian Journal of Agronomy, e4-e4.

Derakhshan, E., Majidi, M. M., Sharafi, Y., \& Mirlohi, A. (2014). Discrimination and genetic diversity of cultivated and wild safflowers (Carthamus spp.) using EST-microsatellites markers. Biochemical Systematics and Ecology, 54, 130-136.

Ekin, Z. (2005). Resurgence of safflower (Carthamus tinctorius L.) utilization: A global view. Journal of Agronomy, 4(2), 83-87.

Emongor, V. (2010). Safflower (Carthamus tinctorius L.) the underutilized and neglected crop: a review. Asian Journal of Plant Sciences, 9(6), 299-306.

FAO. (2020. Janeiro de 2021) Food and Agriculture Organization of the United Nations. Recuperado de: http://faostat3.fao.org/.

Ferreira, M. E., Fernández, J. N., \& Grattapaglia, D. (1998). Introducción al uso de marcadores moleculares en el análisis genético. Federal District, Brazil: Embrapa.

Flemmer, A. C., Franchini, M. C., \& Lindström, L. I. (2015). Description of safflower (Carthamus tinctorius) phenological growth stages according to the extended BBCH scale. Annals of Applied Biology, 166(2), 331-339.

Florien. (2016. Janeiro de 2021) Óleo de Cártamo. Recuperado de: http://florien.com.br/wp-content/uploads/2016/06/\%C3\%93LEODEC\%C3\%81RTAMO.pdf.

Gerhardt, I. F. S. (2014). Divergência genética entre acessos de cártamo (Carthamus tinctorius L.).

Golkar, P. (2014). Breeding improvements in safflower ('Carthamus tinctorius' L.): a review. Australian Journal of Crop Science.

Golkar, P., \& Mokhtari, N. (2018). Molecular diversity assessment of a world collection of safflower genotypes by SRAP and SCoT molecular markers. Physiology and Molecular Biology of Plants, 24(6), 1261-1271.

Gracia, A. B., Esponiza, X. M. O., Márquez, J. P., Camarena, M. G. G., Cervantes, J. M., \& Coronado, L. M. (2010). Guia para produzir cártamo em Sinaloa.

Guidorizzi, F. V. C. (2016). Acúmulo de macronutrientes e produtividade de genótipos de cártamo (Carthamus tinctorius L.) em função da adubação nitrogenada no sistema plantio direto.

Hamdan, Y. A., Pérez-Vich, B., Velasco, L., \& Fernández-Martínez, J. M. (2009). Inheritance of high oleic acid content in safflower. Euphytica, 168(1), 6169.

Hussain, M. I., Lyra, D. A., Farooq, M., Nikoloudakis, N., \& Khalid, N. (2016). Salt and drought stresses in safflower: a review. Agronomy for sustainable development, 36(1), 4.

Kar, G.; Kumar, A.; Martha, M. (2007). Eficiência no uso da água e coeficientes de cultura das culturas oleaginosas da estação seca. Gestão Agrícola de Água. 87.

Kumar, S., Ambreen, H., Variath, M. T., Rao, A. R., Agarwal, M., Kumar, A., \& Jagannath, A. (2016). Utilization of molecular, phenotypic, and geographical diversity to develop compact composite core collection in the oilseed crop, safflower (Carthamus tinctorius L.) through maximization strategy. Frontiers in plant science, $7,1554$.

Litt, M., \& Luty, J. A. (1989). A hypervariable microsatellite revealed by in vitro amplification of a dinucleotide repeat within the cardiac muscle actin gene. American journal of human genetics, 44(3), 397.

Magalhaes, J. R. (2017). Adubação nitrogenada e potássica no desenvolvimento de Carthamus tinctorius L.

Medeiros, P. T. (2011). Viabilidade técnica do biodiesel metílico do óleo de duas variedades de Carthamus tinctorius L. como substituto do diesel de petróleo.

Miah, G., Rafii, M. Y., Ismail, M. R., Puteh, A. B., Rahim, H. A., Islam, K., \& Latif, M. A. (2013). A review of microsatellite markers and their applications in rice breeding programs to improve blast disease resistance. International journal of molecular sciences, 14(11), 22499-22528.

Milach. (2006). Marcadores moleculares em plantas. Porto Alegre: UFRGS.

Mokhtari, N., Sayed-Tabatabaei, B. E., Bahar, M., \& Arabnezhad, H. (2018). Assessment of genetic diversity and population genetic structure of Carthamus species and Iranian cultivar collection using developed SSR markers. Journal of genetics, 97(1), 67-78. 
Research, Society and Development, v. 10, n. 2, e24810212683, 2021

(CC BY 4.0) | ISSN 2525-3409 | DOI: http://dx.doi.org/10.33448/rsd-v10i2.12683

Mondini, L., Noorani, A., \& Pagnotta, M. A. (2009). Assessing plant genetic diversity by molecular tools. Diversity, 1(1), 19-35.

Moura, P. C. S., Bortolheiro, F. P. A. P., Guimarães, T. M., Leal, D. P. V., \& Silva, M. A. (2015). Características gerais e ecofisiologia do cártamo (Carthamus tinctorius). Journal of Agronomic Sciences. Brazil, 4, 136-50.

Mündel, H. H. (1992). Safflower production on the Canadian prairies.

Neto, O. S. S. D. (2020). Seleção, estabilidade e adaptabilidade de progênies de cártamo para produtividade e teor de óleo.

Oelke, E. A., Oplinger, E. S., Teynor, T. M., Putnam, D. H., Doll, J. D., Kelling, K. A., Durgan, B. R., Noetzel, D. M. (1992). Safflower. Alternative FieldCrops Manual. 3.

Omidi, A. H., \& Sharifmogadas, M. R. (2010). Evaluation of Iranian safflower cultivars reaction to different sowing dates and plant densities. World Applied Science Journal, 8(8), 953-958.

Padilha, L., Guimarães, C. T., \& Paiva, E. (2003). Avaliação da pureza genética em sementes de milho utilizando marcadores microssatélites. Embrapa Milho e Sorgo-Circular Técnica (INFOTECA-E).

Paludo, J. T. S., Bonfim-Silva, E. M., da Silva, T. J. A., de Freitas Sousa, H. H., Zanotto, M. D., \& Fenner, W. (2018). Agronomic performance of Safflower genotypes ('Carthamus tinctorius' L.) under different soil bulk density levels in the Oxisol of the Cerrado. Australian Journal of Crop Science, 12 (3), 407.

Queiroga, V. P., Girão, E. G., Albuquerque, E. M. B. (2020) Cártamo (Carthamus tinctorius L.) tecnologias de plantio e utilização. Ed. A Barriguda.

Saadaoui, E., Martín, J. J., Tlili, N., \& Cervantes, E. (2017). Castor bean (Ricinus communis L.): Diversity, seed oil and uses. Oil Seed Crops: Yield and Adaptations under Environmental Stress, 19-33.

Sajedi, N. A. (2012) Impacto do estresse hídrico sobre características bioquímicas de cultivares de cártamo. Fisiologia e Biologia Molecular de Plantas. 18.

Sehgal, D., \& Raina, SN (2011). Carthamus. Wild Crop Relatives: Genomic and Breeding Resources , 63-95.

Shahrokhnia, M. H., \& Sepaskhah, A. R. (2016). Effects of irrigation strategies, planting methods and nitrogen fertilization on yield, water and nitrogen efficiencies of safflower. Agricultural Water Management, 172, 18-30.

Sharifi, R. S., Namvar, A., \& Sharifi, R. S. (2017). Grain filling and fatty acid composition of safflower fertilized with integrated nitrogen fertilizer and biofertilizers. Pesquisa Agropecuária Brasileira, 52(4), 236-243.

Silva, C. J. D. (2013). Caracterização agronômica e divergência genética de acessos de cártamo.

Silveira, L., Júnior, E. S., Dal Pozzo, D. M., Santos, R. F., Tokura, L. K., \& Secco, D. (2017). Influência alelopática do extrato aquoso de folhas de Citronela (Cymbopogon) sobre a germinação e desenvolvimento inicial de quatro genótipos conhecidos de Cartamo (Carthamus tinctorius L.). Acta Iguazu, 6(5), 197206.

Singh, V., \& Nimbkar, N. (2016). Safflower. In breeding oilseed crops for sustainable production (pp. 149-167). Academic Press.

Singh, V, \& Nimbkar, N. (2007). Safflower (Carthamus tinctorius L.), In: SINGH, R, J: Genetic Resources Chromossome Engineering, and Crop Improvement: Oil Crops, Boca Raton. 8.

Vieira, E. A., Fialho, J. D. F., Faleiro, F. G., Bellon, G., Fonseca, K. G. D., Carvalho, L. J. C. B., \& Silva, K. N. D. (2008). Divergência genética entre acessos açucarados e não açucarados de mandioca. Pesquisa Agropecuária Brasileira, 43(12), 1707-1715.

Zoz, T. (2015). Avaliação de genótipos de cártamo quanto ao desempenho agronômico, divergência genética e produtividade da ág ua. 